\title{
EBUSSUUD EFENDİ'NIN FARSÇA BİR MANZUM FETVASI
}

\section{Muhittin ELİAÇIK*}

Geliş Tarihi: Ă̆ustos, 2016

Kabul Tarihi: Aralık, 2016

$\ddot{O} \mathbf{z}$

Fetva kelimesi yiğit, genç, kavî manasındaki fetâ kökünden gelmekte ve sual edilen müşkil bir meselenin hükmünün şeyhülislam veya müftüce kaynağından araştırılarak ortaya konulmasını anlatmaktadır. Bu kelime, fikhî anlamını müşkil bir meseleyi güçlü bir cevapla izah etmekten dolayı kazanmıştır. Fetva verme, zor ve ciddi bir işlem olduğundan fetvayı veren için 'hallâl-1 müşkilât, müşkil-güşâ' gibi tabirler kullanılmıştır. Fetva kitapları çeşitli konularda kritik bilgiler içeren önemli kaynaklardır. Osmanlıda beş asırlık bir sürede 129 şeyhülislamın görev yaptığı ve verdikleri fetvaların fikhî ve edebî yönden çok zengin bir malzeme ortaya koyduğu görülmektedir. Hâl-i hazırda elimizde 22 tane fetva mecmuası mevcut olup, bunlar ise yapılacak çok yönlü çalışmaları beklemektedir. $\mathrm{Bu}$ kitaplarda hukukî konuların öncelikli olduğu düşünülebilirse de dil ve edebî derinliğin de ciddî bir seviyede olduğu söylenebilir. Bazı fetva kitaplarında rastlanan manzum fetvalar bu heyecanın boyutunu daha da artırıcidır. Manzum fetva verenlerin en önde geleni Şeyhülislam Ebussuud Efendi'dir. $\mathrm{Bu}$ çalışmada onun tespit edilen bir Farsça manzum fetvası tanıtılmaktadır.

Anahtar Sözcükler: Ebussuud Efendi, Farsça, fetva, manzum fetva.

\section{A PERSIAN FATWA IN POETRY FORM WHICH WAS WRITTEN BY EBUSSUUD EFENDI}

\begin{abstract}
Fatwa word, comes from the root fetai in the brave, young, strong sense. Fatwa, is disclosed of provision of a difficult issue by the Sheikh al-Islam or mufti investigated from sources. This word gained meaning of the fiqh due to explain a difficult issue with a strong answer. Because fatwa process is a difficult procedure for fatwa giver 'hallâl-1 müşkilât, müşkil-güşâ/solve challenges' etc. terms are used. Fatwa books are very important sources on various subjects contain very critical information. In the Ottoman Empire 129 sheikh al-Islam mission did during a period of five centuries and their fatwas juristical and literary aspects revealed a very rich material. Today available is 22 fatwa book and these books is waiting versatile studies. Although in these books is firstly juristic issues; also exciting language and literary depth and breadth located. Especially in some fatwa books located in poetry form fatwas, this excitement is further increases. The most prominent of the owners in poetry form fatwas is of Sheikh al-Islam Ebussuud Efendi. In this study are introduced his a poetry form fatwa which was written as Persian.
\end{abstract}

Keywords: Fatwa, poetry form fatwa, Persian, Ebussuud Efendi.

\footnotetext{
*Prof. Dr.; Kırıkkale Üniversitesi, Fen Edebiyat Fakültesi, Türk Dili ve Edebiyatı Bölümü, meliacik63@yahoo.com.
} 


\section{Giriş}

Yiğit, genç, kavi anlamındaki fetâ kökünden gelen fetva kelimesi, bir müşkili açıklayıp çözen güçlü cevaptır. İslâm devletlerinde fetvaya büyük önem verilmiş ve mühim işlere müftülere danışılarak girişilmiştir. Dört Halife döneminde kadılık ve müftülük valilerde toplanmış, daha sonra fetva ve yargılama işleri birbirinden ayrılmış, Emevî halifesi Ömer bin Abdülaziz zamanında iftâ teşkilatı resmen kurulmuş (Atar, 1991: 122-126), Memlûkler döneminde ise müftüler devlet yönetiminde etkin biçimde yer almışlardır (Uzunçarş111, 1984: 387). Osmanlı' da savaş, barış, ıslahat, halifenin hâl'i, eşkıyalık yapanların katli vb. olaylar fetva konusu olmuş ve çıkarılan örfi kanunnamelerde şeyhülislamın fetvası istenmiş, özel hukuku ilgilendiren fetvalar kişilerin, kamu hukukunu ilgilendiren fetvalar idarecilerin isteği üzerine verilmiştir (Atar, 1995: 490). F1kıh kitaplarının sistematiğinde düzenlenen fetva kitaplarında cevaplar genellikle Hanefi mezhebine göre verilmiş, meseleler kaynağı belirtilerek olur, olmaz, câizdir diye cevaplanmış, bazı kitapların kenarlarına ek fetvalar yazılmıştır. Osmanlı fetva kitapları genellikle 17-18. yüzyıllara ait olup vakıf, nikâh, talâk, bey' ü şirâ, şehâdât bapları en çok mesele yer alan baplar olmuştur. Fetva kitaplarının Ebussuûd, Müeyyedzade Abdurrahman, Sa'dî Çelebi, Zekeriyazâde Yahya, Balizâde Mustafa, Çatalcalı Ali, Seyyid Feyzullah, Menteşizade Abdurrahim, Yenişehirli Abdullah ve Dürrizade Mehmed Efendilere ait olanları, Osmanlı kadılarınca en çok başvurulan kitaplar olmuştur. Osmanlı fetvalarında erkekler için Zeyd, Amr, Bekir, Halid; kadınlar için de Hind, Zeyneb, Hatice, Ümmü Gülsüm gibi hayalî isimler kullanılmıştır.

\section{Manzum Fetva}

Osmanlı'da 16-18. yüzyıllarda bazı şeyhülislam veya müftüler kendilerine nazmen sorulan meselelere nazmen cevap vermişlerdir. Ebussuûd Efendi’nin fetvaları ile başladığ 1 düşünülen ${ }^{1}$ bu uygulamada sanat endişesi güdülmemiş, genellikle fe'ilâtün mefâ'ilün fe 'ilün; fe 'ilâtün fe'ilâtün fe 'ilün gibi kısa kalıplar kullanılmış, belli bir şekil ve muhteva izlenmiştir. Şu ana kadar tarafımızca otuza yakın manzum fetva tespit edilmiş ve bunların sayıca en çoğu Şeyhülislam Ebussuûd Efendi’ye ait bulunmuştur. Manzum fetvalar genellikle 4-10 beyit arasında yazılmış, ancak 52 beyite çıkanları bile bulunmuştur. ${ }^{2}$ Manzum fetvalar özellikle giriş bölümlerinde belli bir şekil ve üslup üzerine olmuş ve hitap edilen şeyhülislam için: sadefçe-i kevn, yegâne-i dehr, hâtemü'l-müctehidîn, ukde-güşâ-yı işkâl, kalem-perdâz-ı hikem-sâz-ı dîn,

1 Ebussuud Efendi ile Kanuni arasındaki bir karınca fetvası meşhurdur. Kanuni Sultan Süleyman bir gün sarayın hasbahçesinde gezerken taze ayva ağacını karıncaların sardığını görüp karıncaların katli için fetva istemiş ve bunu Şeyhülislam Ebussuûd Efendi'ye: Dırahta ger ziyan itse karınca - Günahı var mıdır anı kırınca şeklinde nazmen sormuş, o da: Yarın Hakkun huzûrına varınca - Süleymandan hakın alır karınca diye nazmen cevap vermiştir.

${ }^{2}$ Bostanzâde Muhammed Efendi’nin kahve üzerine verdiği fetva böyledir. 
hallâl-ı müşkilât, re'îs-i mecâmi'-i 'ulemâ, ser-efrâz-l fuzalâ, ser-efrâz-ı zümre-i 'ulemâ, re'îs-i eimme-i 'ulemâ, müftü-i müşkil-i savâb u hatâ,kâ'id-i rekb-i cümle-i fuzalâ, ukde-güşây-l müşkil-i nâs gibi sıfatlar kullanılmıştır. Manzum fetvalar edebî sanatlarca fakir olmakla beraber, sadece vezinli-kafiyeli manzumeler olarak görülmeleri de doğru değildir. Bu fetvalar özellikle giriş bölümlerince edebî sanatlar bakımından iddialıdır. Manzum fetva geleneğinde büyük bir yeri olan Ebussud Efendi'nin binlerce fetvası içinde bir de Farsça manzum fetvası bulunmaktadır. Osmanlı'da Türkçe manzum fetvalara göre Farsça manzum fetva sayısı çok azdır. Şu ana kadar bilinen tek fetva olup o da Ebussuûd Efendi'ye aittir. Öte yandan fetva kitaplarında meraklılarca kaydedilmiş, kime ait olduğu belli olmayan Arapça bir rubâî-müstezad manzum fetva da tespit edilip yayımlanmıştır. ${ }^{3}$

\section{Ebussuûd Efendi}

Ebussuûd Efendi, Osmanlı Devleti'nde 1545-1574 tarihleri arasında 29 yıl ile en uzun süre şeyhülislamlık yapmış bir isim olup tefsir, hukuk, dil/edebiyat konularında 30'a yakın eser vermiş, fikıh ve tefsirde Müftü's-sakaleyn, Müftü'l-enâm, Ebĥu-Hanîfe-i Sânî, Muallim-i Sânî, Allâme-i Kül, Hoca Çelebi gibi unvanlarla anılmıştır. Asıl adı Muhammed, künyesi ise Ebussuûd'dur. 896/1490'da İstanbul yakınlarındaki Meteris (Metris-Müderris) köyünde doğmuştur. Babası, Sultan II. Bayezid'in Amasya sancak beyliğinde sevgisini kazanmış ve cülusunda İstanbul'a çağrılıp kendisi için bir tekke yapılmıştır. Tahsilini önce babasından, daha sonra da Müeyyedzâde Abdurrahman Efendi, Mevlânâ Seydî-i Karamânî ve İbni Kemal'den almıştır. Sırayla İnegöl İshak Paşa, Dâvud Paşa, Mahmud Paşa, Gebze Vezir Mustafa Paşa medreselerinde görev yapmış, Bursa Sultâniye pâyesi verilmiş, 1528'de Medâris-i Semâniyye'den Müftü Medresesine müderris olmuş, beş yıl bu görevde kalıp önce Bursa, sonra 1533'de İstanbul kadısı, 1537'de Rumeli kazaskeri olmuştur. Sekiz yıllık Rumeli kazaskerliğini müteakiben 1545 'te şeyhülislam olmuştur. Kendisiyle birlikte şeyhülislamlığın itibarı artmış ve maaş günlük 200 akçeden -Bayezid müderrisliğiyle birlikte- 500 akçeye yükselmiştir. Ebussuûd Efendi, tefsirini tamamlayınca bu maaş 600 akçe olmuş, böylece şeyhülislamlık her yönden kazaskerliğin önüne geçmiştir. Müderris ve Mevleviyet kadılarını da tayin etme yetkisi artık şeyhülislama geçmiş ve şeyhülislam olabilmek için önce Rumeli kazaskeri olma şartı getirilmiştir. Ebussuûd Efendi 1574 tarihinde vefat edip Eyüp Camii civarında kendi yaptırdığı sübyan mektebinin haziresine defnedilmiştir. ${ }^{4}$ Tasavvuf, kelâm ve felsefe konularıyla ilgilenmemiş, tasavvufa dair çok sert sözler sarf etmiş, tekkelerde Yûnus'un şiirlerinin

\footnotetext{
${ }^{3}$ M.Eliaçık, Rubâî-müztezâd şeklinde yazılmış Arapça bir manzum fetva, JOHS, June 2016, pp.709-717.

${ }^{4}$ Vefatı için düşürülen tarih: "Monla Ebussu'ûda ola makâm cennet=982/1574” (Milli Kütp. 06 Hk 3756, vrk.62a)
} 
okunmasını küfr-i sarîh saymış, sufilerin devranını 'kâfirlerin horoz tepmesi' olarak nitelemiş, devranı ibadet gören sûfîleri mürtedlikle suçlamış, Şeyh İsmâil Ma'şûkî, Muhyiddin Karamânî ve Hamza Bâlî hakkında şeriata aykırı görüşlerinden dolayı idam fetvası vermiştir. Türkçe, Arapça, Farsça şiirler yazmış, kendisine nazmen sorulan meselelere nazmen cevaplar vermiştir. Kınalızade ve Riyâzî tezkirelerinde şiirinden kısaca bahsedilmiştir. Şiirleri sanat yönünden iddialı olmasa da Arapça şiirleri nispeten iddialıdır. Tefsirde: İşâadü'l-akli's-selîm, fikıhta: Fetâvâ-yı Ebussuûd, Ma 'rûzât, Risâle fî-vakfi'l-menkūl ve'n-nukūd, Bidâatü'l-kadî li-ihtiyâcihi fil-müstakbel ve'l-mâzî, Fetâvâ Kâtiblerine Tenbih, el-Fetva'l-müteallika bi-beyâni'l-vakti'lmu 'tebere li'l-hasâd ve istihkāki'l-gallât, Gamezâtü'l-melîh fî-evveli mebâhisi kasri'l-âmm mine't-Telvîh, Sevâkıbü'l-enzâr fì evâili Menâri'l-envâr, Hasmu'l-hilâf fi'l-meshi ale'l-hifâf, Risâle fî-vakfi'l-arâzî ve ba'zi ahkâmi'l-vakf, Risâle fî-tescîli'l-evkaf, Risâle fî-vakfi't-tavâhîn ale'l-arzi'l-mevkufe li'l-gayr, Öşür Risâlesi; dil/edebiyatta: Galatât-ı Ebussuûd, el-Kasîdetü'lmîmiyye, el-Kasâidü'l-Arabiyye, Kasîde fî-risâi's-Sultân Süleymân, Münşeât-ı Ebussuûd, akaidde: Risâle fí-beyâni'l-kazâ ve'l-kader, Duânâme adlı eserleri yazmıştır (Atai, 1268: 183; A.Rifat, ts. 23-26; Akgündüz, 1994: 365-371).

\section{Ebussuûd Efendi’nin Farsça Manzum Fetvası}

Ebussuûd Efendi, Osmanlı'da manzum fetva konusunda en öne çıkan bir şeyhülislam olup her türlü konuda fetva vermiş, bunlar arasında Arapça ve Farsça olanlar da yer almış, bunların arasında manzum olanlar da bulunmuştur. İşte bunlardan birisi aşağıdaki Farsça manzum fetvadır. Bu fetvada hayali olarak, on yıl içinde istenilip alınacak her bir kadının üç talakla boş olacağına dair bir yemin edildiğinden bahisle, bu yeminin nasıl geçersiz olacağı sorulmuştur. Ebussuud Efendi bu suale: “İmam'a göre, taleple (isterim demekle) yemin bozulur; mezhep içindeki farklı görüşlere göre beklemeksizin, diğer mezheplere göre ise delilsiz olarak, hemen nikâh akdi yapılır." diye cevap vermiştir. Bu fetvanın, ismi belirsiz başka bir müftü tarafından verilmiş ikinci manzum cevabında ise bu davranışın fuzuli nikâh akdi kapsamına girdiği ve geçersiz durumda bulunduğu belirtilmiştir. ${ }^{5}$ Fetva şöyledir:

$$
\begin{aligned}
& \text { fe 'ilâtün mefâ 'ilün fe 'ilün } \\
& \text { Çi nüvîsed cevâb-1 în fetva }
\end{aligned}
$$

\footnotetext{
${ }^{5}$ Fuzuli nikâh, boş ve geçersiz nikâhtır. Bu nikâha göre, iki taraftan fuzuli olan bir şahsın yapacağı nikâh akdi geçerli olmadığı gibi, bir tarafın asil, vekil veya mücbir veli; diğer tarafın ise fuzuli bir şahıs olduğu nikâh da geçerli değildir. (Ö.Nasuhi Bilmen, Hukûk-ı İslâmiyye ve Istılâhât-ı Fıkhiyye Kamusu, C.2 (2.bölüm 4.kitap), İstanbul 1949-52)

6 İBB Atatürk Kitaplığı, Bel_Yz_K.000125, vrk.57b; Tokat İHK, 60 Hk 233/2 vrk.103a; Nev’̂̂-zâde Atâyî, Hadâiku'l-hakâik fî-Tekmileti'ş-Şakâik, İstanbul 1268, s.187. Atâî Zeyli'nde fetvanın baş kısmına: Şeyhü'l-íslâm-ı 'umde-i fuzalâ - Hâce-i dîn ü dâver-i dünyâ - Müftü-i 'asr u kıdve-i 'âlem mısraları eklenmiştir. Fetvanın sonundaki ikinci cevap ise sadece Atatürk Kit. nüshasında mevcuttur.
} 
Med-dih-i dehr ü zübde-i a'lâm

Zeyd der-hâlet-i kemâl-i bülûğ

Gûyed ez-rûy-1 ihtimâm-1 tamâm

Tâ-be dih sâle her zenî hâhem

Be-talâk-1 selâse bâd harâm

Fesh yâ $^{8}$ inhilâl-i în-sevgend ${ }^{9}$

Hîç mümkin şeved ${ }^{10}$ be-kavl-i İmâm

Ey ki gûyed cevâb ecreş-rân ${ }^{11}$

Bi-dehed Zü'l-Celâli ve'l-ikrâm

El-cevâb:

Ger husûs-1 'ibâret-i hâlif

Hem-çünîn ${ }^{12}$ şod be-vakt-i sevk-i kelâm

Be-taleb mî-şeved yemîn münhal

Ba'd-ez-ân ${ }^{13}$ 'akd mî-resed be-tamâm

Bî-temessük ${ }^{14}$ be-mezheb-i digerân

Bî-tevakkuf be-gayr-i re’y-i İmâm

Goft în-râ Ebu's-Su'ûd el-hakîr

Kemterîn-i 'ibâd-1 Rabbü'l-enâm

Hüccet-i hakk u pîşvây-1 halk

Muktedâ-yı meşâyih-i İslâm

\footnotetext{
${ }^{7}$ Tokat İHK: “Zübde-i kıdve-i kirâm-1 enâm”. Bu beytin ikinci mısraı Atâî Zeyli’nde yoktur.

${ }^{8}$ Atâî Zeyli: 'Fesh u yâ'

9 Tokat İHK: "Enderîn sâlhâ tezevvüc-i Zeyd"

${ }^{10}$ Tokat İHK, Zeyl-i Atâî: 'buved'

${ }^{11}$ Tokat İHK: "Her ki gûyed cevâb-1 în fetva"

${ }^{12}$ Zeyl-i Atâî: 'În-çünîn'

${ }^{13}$ Tokat İHK: "Ba'd-ez-în"

${ }^{14}$ Tokat İHK: 'Bî-tereddüd', Zeyl-i Atâî: 'Bî-temessük'
} 
"Büyük âlimlerin süsü, zamanın yardım edicisi, bu fetvanın cevabını nasıl yazdı? Zeyd büluğ hâlinin olgunluğunda tam bir ihtimamla: On yıla dek istediğim her bir kadın üç talakla bana haram olsun dediğinde bu yeminin bozulması veya çözülmesi İmam'ın görüşüne göre hiç mümkün olur mu? Her kim cevap verirse celal ve ikram sahibi olan Allah onun ecrini versin. Cevab: Eğer yemin eden, sözü söylerken aynen bu şekilde söylemişse, taleple yemin bozulur, ondan sonra akit, mezhep içinde imamın görüşünde olmayanlara göre hemen, diğer mezheplere göre bir delil gerekmeksizin tamamlanır. Bunu, Hakkın delili, halkın lideri, İslâm âlimlerinin önderi Ebussuûd söyledi. O, âlemlerin Rabbinin kulları içinde çok değersiz bir kuldur. “

Fetvanın sonunda, Muhammed bin Cemâl tarafından yazılmış, sadece Atatürk Kitaplığı nüshasinda bulunan manzum cevap:

El-cevâb

Ger cevâb-1 savâb mî-hâhî

Gûş-râ sûy-1 men bi-nih be-tamâm

Hükm-i în-'akd-i hılf nezd-i fakîr

Mu’teber şod be-asl-1 ‘örf-i enâm

Zeyd sühan-râ murâd-1 hıtbe şeved

Nezd-i Kazbî be-ittifâk-1 merâm

Geşt bât1l be-asl-1 tavr-1 yemîn

Bî-tevakkuf be-hall u fesh-i kelâm

Der-tezevvüc buved murâd diger

Be-zenî hılf mî-resed be-tamâm

Bî-taleb nîz mî-şeved maksûd

Çün taleb bûd muktezâ-yı makâm

Çâre-i 'akd-1 şart-1 bî-tahlîl

Be-fuzûlî şeved be-kavl-i İmâm

Goft în-râ Muhammedübni Cemâl

Kemterîn-i 'ibâd-1 Rabb-i selâm 
"Eğer doğru cevabı istersen kulağı tamamen benden yana tut. Bu yemin akdinin hükmü bu fakirin nezdinde halkın örfüne göre muteberdir. Kazbî nezdinde Zeyd'in sözü dünür niyetiyledir; (ama) yemin şeklinden dolayı söz fesholduğundan hemen batıla dönüş̧ü. Evlenmede murat değişir ve bir kadına yemin tamama erer. Maksat, talepsiz de olur, talep durum gereğincedir. Çözümsüz şart akdinin çaresi, İmamın görüşüne göre fuzulidir. Bunu Rabb'in kullarının en değersizi Muhammed übni Cemâl söyledi."

Ebussuûd Efendi’nin aynı sayfada, yukarıdaki ikinci manzum cevaba yakın bir mensur fetvası daha bulunmaktadır ve şöyledir: Zeyd eger gayr-ez Hind her avrat-ı dîger ki tezevvüc konem be-her-vech ki bâşed fuzûlî ve gayr-i fuzûlî be-talâk-ı selâse mutlak bâşed ${ }^{15}$ didükden sonra Hind-i mezbûre fevt olıcak Zeynebi tezevvüce be-tarîk-i şer'î var mıdur? El-cevâb: İbâreti hemîn zikr olunan ise bir kimesne bir hatun fuzûlî yerinde nikâh idüp şart vâki' olmak ile yemîn münhalle olur ammâ Zeydün mülkine dâhil olmamak ile ü̧̈ talâk vâki' olmaz andan sonra tekrâr fuzûlî nikâh olunup Zeyd fi'li ile kabûl idicek yâhûd kavli ile kabûl idicek ol hatun hakkında yemîn bâtıladur. ${ }^{16}$ : "El-cevap: Söz aynen bu şekilde söylenmişse, bir kimse bir hatunu fuzuli olarak nikâh edip şart gerçekleşirse o yemin boş olur, ama Zeyd'in mülküne girmemekle üç talak gerçekleşmez; ondan sonra tekrar fuzuli nikâh yapılır. Zeyd fiili veya sözü ile kabul edince o hatun hakkındaki yemin bâtıldır."

\section{Sonuç}

Şairliği ile öne çıkmış bir şeyhülislam olan Ebussuûd Efendi bu kimliğini fetvalarında da sıkça göstermiştir. Osmanlı' da manzum fetva geleneğinin büyük ölçüde kendisiyle başladığı söylenebilir. Muhtelif fetva kitaplarında rastlanan manzum fetvaların çoğunun Ebussuûd Efendi'ye ait olması, onun bu sahada öncü durumda bulunduğuna işarettir. Osmanlı'da manzum fetvaların sayısı mensur fetvalara göre çok az olduğundan bunlar fetva kitaplarında bir süs ve çeşni olarak yer almış ve birer numune olarak kitapların baş ve sonlarına konulmuştur. Hatta bazı kitaplarda diğer fetvalarla karışmamak için özel çerçeveye alındıkları da görülmektedir. Osmanlı şeyhülislam veya müftüleri arasında Ebussuûd Efendi'nin dışında başka bir Farsça manzum fetva bilinmemektedir. Bu makalede tanıtılan Farsça manzum fetva, manzum fetvalar arasında hem konu, hem uzunluk, hem de çift cevaplı olması bakımından yegânedir. Bu makalede müstakil biçimde ele alınması da bundan dolayıdır. Şu ana kadar, Ebussuûd Efendi'nin imzasıyla yazılmış altı tane manzum fetva tespit edilmiş olup, bunların arasında yer alan Farsça manzum fetva hem Ebussuûd Efendi'nin, hem de Osmanlı manzum fetvalarının

\footnotetext{
15 “eğer Hind'den başka -fuzuli veya gayr-i fuzuli olsun- evleneceğim her bir kadın üç talâkla boş olsun”

${ }^{16}$ İBB Atatürk Kitaplığı, K.000125, vrk.57b.
} 
bilinen tek örneğidir. Çeşitli yazma nüshalarda farklı şekillerde karşımıza çıkan bu fetva, nüshaların birisinde de sonuna başka birisince yazılmış manzum bir cevapla görülmektedir. $\mathrm{Bu}$ Farsça fetvanın bazı kelimeleri nüshalarda farklı olup, bu da farklı anlamlara yol açabilmektedir. Ebussuûd Efendi'nin yukarıdaki fetvasında hayali olarak, on yıl içinde istenilip alınacak her bir kadının üç talakla boş olacağına dair bir yemin edildiği, bu yeminin nasıl geçersiz olacağı

sorulmuş ve cevabında: "İsterim demekle yemin bozulup, mezhepteki farklı görüşlere göre beklemeden, diğer mezheplere göre ise delilsiz olarak, hemen nikâh yapılır." denilmiş; ikinci cevapta ise bu davranışın fuzuli nikâh akdine girdiği belirtilmiştir.

\section{Kaynaklar}

AHMED RIFAT, Devhatü'l-Meşâyih Maa Zeyl. İstanbul. tsz.

AKGÜNDÜZ, A. (1994). Ebüssuud Efendi, Diyanet İslâm Ansiklopedisi.

ATÂ̂̂I (1268). Zeyl-i Şakâik li-Atâyî. İstanbul.

ATAR, F. (1991). İslâm Adliye Teşkilâtı. Ankara: Diyanet İşleri Bşk. Yayınları.

ATAR, F. (1995). Fetva, Diyanet İslâm Ansiklopedisi. İstanbul.

UZUNÇARŞILI, İ. H. (1984). Osmanlı Devleti Teşkilatına Medhal, Ankara: TTK. 